\title{
Oxidase Enzyme Activities and Their Correlations with Antioxidative Stress Biomarkers in Patients with Acute Coronary Syndrome in Bangladesh
}

\author{
Nourin Ferdausi, Md. Eahsanul Karim Anik, Nabila Nawar Binti, Laila N. Islam* \\ Department of Biochemistry and Molecular Biology, University of Dhaka, Dhaka, Bangladesh \\ Email: *laila@du.ac.bd
}

How to cite this paper: Ferdausi, N., Anik, Md.E.K., Binti, N.N. and Islam, L.N. (2020) Oxidase Enzyme Activities and Their Correlations with Antioxidative Stress Biomarkers in Patients with Acute Coronary Syndrome in Bangladesh. World Journal of Cardiovascular Diseases, 10, 163-177. https://doi.org/10.4236/wjcd.2020.104017

Received: March 6, 2020

Accepted: April 13, 2020

Published: April 16, 2020

Copyright $\odot 2020$ by author(s) and Scientific Research Publishing Inc. This work is licensed under the Creative Commons Attribution International License (CC BY 4.0).

http://creativecommons.org/licenses/by/4.0/ (c) (i) Open Access

\begin{abstract}
Acute coronary syndrome (ACS) is a range of conditions associated with decreased blood flow in the coronary arteries resulting from sudden rupture of atherosclerotic plaques. Several studies have found that oxidative stress is involved in the initiation and progression of atherosclerosis. The role of oxidase enzymes and antioxidative stress biomarkers in these processes needs further attention. In this study, a total of 120 participants were enrolled which comprised 60 ACS patients and 60 control subjects. The major oxidase enzyme, xanthine oxidase, which plays a pivotal role in the generation of reactive oxygen species (ROS), showed significantly higher activities in both serum $(158.03 \pm 43.30 \mathrm{mU} / \mathrm{mL})$ and red blood cells $(\mathrm{RBC})$ lysate $(309.07 \pm 75.73$ $\mathrm{mU} / \mathrm{mL}$ ) of the ACS patients compared to controls, $48.51 \pm 13.41 \mathrm{mU} / \mathrm{mL}$ and $184.10 \pm 70.14 \mathrm{mU} / \mathrm{mL}$, respectively. The nicotinamide adenine dinucleotide phosphate (NADPH) oxidase and myeloperoxidase, both of which are major contributors to ROS production, showed significantly higher activities in patients $(14.13 \pm 3.38 \mathrm{U} / \mathrm{L}$ and $10.9 \pm 3.3 \mathrm{U} / \mathrm{mg})$ than in controls, $6.90 \pm$ $1.94 \mathrm{U} / \mathrm{L}$ and $5.9 \pm 1.5 \mathrm{U} / \mathrm{mg}$, respectively. Ceruloplasmin, an emerging biomarker of inflammation, showed significantly higher activity in patients (83.8 $\pm 26.2 \mathrm{U} / \mathrm{L}$ ) compared to controls, $70.0 \pm 18.9 \mathrm{U} / \mathrm{L}$. The antioxidant enzyme glutathione reductase showed significantly lower activity in patients than controls, $60.7 \pm 47.8 \mathrm{U} / \mathrm{mL} / \mathrm{min}$ and $85.2 \pm 49.5 \mathrm{U} / \mathrm{mL} / \mathrm{min}$, respectively. Evaluation of cardioprotective biomarkers nitric oxide and high-density lipoprotein-cholesterol (HDL-C) showed significantly lower values in patients. Correlation analyses between these parameters further corroborated increased oxidative stress in patients. These findings suggest that excessive productions of ROS by the oxidase enzymes cause an imbalance between
\end{abstract}


oxidants and antioxidants in favor of oxidants leading to increased oxidative stress in patients with ACS.

\section{Keywords}

ACS, Xanthine Oxidase, NADPH Oxidase, Ceruloplasmin, Glutathione

Reductase

\section{Introduction}

Cardiovascular diseases (CVD) are a major contributor to global deaths in developed countries, and its prevalence is rising in developing countries [1]. According to a large scale study, the prevalence of CVD is at its peak in Bangladesh and its associated risk factors such as hypertension and diabetes are on the rise [2]. The majority of cardiovascular deaths are attributable to coronary artery disease (CAD) which is the blockage of one or more arteries that supply blood to the heart, usually due to atherosclerosis. The most ominous manifestation of CAD is acute coronary syndrome (ACS) which causes a sudden reduction in myocardial perfusion, comprising unstable angina (UA), non-ST-elevation myocardial infarction (NSTEMI) and ST-elevation myocardial infarction (STEMI).

Several studies have found that the most common risk factor for atherosclerosis is increased production of reactive oxygen species (ROS) along with an impaired endogenous antioxidant mechanism, a phenomenon also termed as oxidative stress [3] [4]. Although the impact of oxidative stress is well established, the molecular source of ROS is ambivalent. The present study was designed to test the hypothesis that oxidative stress may occur due to the upregulation of oxidase enzymes such as xanthine oxidase (XO), NADPH oxidase, myeloperoxidase (MPO), and downregulation of antioxidant enzymes such as glutathione reductase (GR). Other prominent biomolecules may also give some insight into the generation of oxidative stress such as ceruloplasmin $(\mathrm{Cp})$, nitric oxide $(\mathrm{NO})$ and HDL-C.

The NADPH oxidase or NOX is membrane-associated enzyme complex that catalyzes the 1-electron reduction of oxygen using NADPH as the electron donor [5]. NOX family enzymes are one of the major contributors to ROS production. XO catalyzes the oxidation of hypoxanthine and xanthine to uric acid in the process of purine metabolism which is the first biological mechanism to be identified as a producer of ROS [6]. MPO, a pro-inflammatory enzyme found in abundance in ruptured plaque [7], catalyzes the hypochlorite formation from chloride and hydrogen peroxide. MPO has been demonstrated to be involved in multiple low-density lipoprotein (LDL) oxidation pathways. It limits NO bioavailability, resulting in endothelial dysfunction [8].

Reduced glutathione (GSH) is one of the first lines of defenses against oxidative stress, acting as a non-enzymatic antioxidant [9]. GR plays an essential role in the redox cycle of glutathione by regenerating GSH from its oxidized form, 
using NADPH. Cycling between GSH and oxidized glutathione (GSSG) is used to remove free radicals produced by the metabolism of potent toxins and to protect cells against oxidative injuries [10]. NO, another non-enzymatic antioxidant synthesized by nitric oxide synthase (NOS), is a major contributor to the normal homeostasis of the cardiovascular system. NO produced by the endothelial isoform of NOS (eNOS), is principal determinant of endothelium-dependent relaxation and regulator of vascular tone. Furthermore, NO inhibits platelet aggregation, adhesive molecules expression, and regulates cell proliferation and differentiation at the vascular wall [11].

Although cholesterol is essential for life, its excessive amount in the blood can increase the risk for stroke and heart disease [12]. Blood cholesterol has several major constituents, including very-low-density lipoprotein-cholesterol (VLDL-C), low-density lipoprotein-cholesterol (LDL-C), and HDL-C. It has been found that high levels of triglyceride combined with high levels of LDL-C and low levels of HDL-C speed up atherosclerosis [12].

Ceruloplasmin, the biggest circulating copper carrier is a ferroxidase enzyme capable of oxidizing ferrous ions to less toxic forms of ferric ions [13]. It has been found that $\mathrm{Cp}$ is also an acute-phase protein in inflammation setting [14]. Increased levels of $\mathrm{Cp}$ are associated with the production of reactants for oxidation, i.e. superoxide and hydrogen peroxide [15]. Many studies have found that $\mathrm{Cp}$ levels have been increased in patients with cardiovascular disorders such as coronary heart disease (CHD) and MI [16] [17]. The role of Cp in lipoprotein oxidation and progression of atherosclerotic lesions has not been directly evaluated and is an important focus for future studies.

Oxidative stress and endothelial dysfunction underlie the pathophysiology of ACS and this study may provide some insight into the development of ACS by the assessment of major oxidase enzymes, and their effects on GR, HDL-C, nitric oxide and ceruloplasmin in the blood.

\section{Methods}

\subsection{Subjects}

A total of 120 subjects were enrolled in this investigation comprising of $60 \mathrm{pa}$ tients suffering from acute coronary syndrome (ACS), admitted to the coronary care unit (CCU) of Dhaka Medical College Hospital. The diagnosis was made by expert physicians based on characteristic electrocardiogram and troponin changes. Any patient ailed with diabetes mellitus, infections, impaired renal or liver functions, or any other chronic inflammatory conditions was excluded from the study to avoid false positive results. A group of 60 healthy subjects, from the local community, was enrolled as the control group who did not have any prior history of diabetes mellitus or ACS.

\subsection{Ethical Clearance}

This study was approved by the ethical review committee of the Faculty of Bio- 
logical Sciences, University of Dhaka, Bangladesh. Prior to data collection, each individual was informed about the objectives and significance of the study. Only the full consenting volunteers were enrolled.

\subsection{Study Period and Blood Sample Collection}

This study was conducted from February 2018 to April 2019. About $10 \mathrm{~mL}$ of venous blood was drawn from each subject, $5 \mathrm{~mL}$ was collected in a lavender capped tube containing EDTA for plasma collection and the rest was taken in a glass tube for serum collection. The serum and plasma were separated, collected in small aliquots and stored at $-20^{\circ} \mathrm{C}$ until analyzed.

\subsection{Preparation of RBC Lysate}

Fresh blood $(200 \mu \mathrm{L})$ was taken in a tube and the cells were washed twice with an excess of normal saline. The pellet was suspended with $800 \mu \mathrm{L}$ of ice-cold nano-pure water and incubated at $4^{\circ} \mathrm{C}$ to lyse the RBCs. The preparation was centrifuged and the supernatant was collected.

\subsection{Assay of Xanthine Oxidase Activity}

Xanthine oxidase (XO) activity was measured by the method of Bergmeyer et al. [18]. Briefly, an aliquot of $25 \mu \mathrm{L}$ of serum or RBC lysate was added to $475 \mu \mathrm{L}$ of phosphate buffer. The reaction was started with the addition of $250 \mu \mathrm{L}$ of xanthine solution and absorbance was recorded at $290 \mathrm{~nm}$ using a Shimadzu UV Spectrophotometer. The increase in absorbance was recorded for 5 minutes. XO activity was expressed as $\mathrm{mU} / \mathrm{mL}$, which was defined as the amount of enzyme that catalyzed the oxidation of xanthine yielding 1.0 micromole of uric ac$\mathrm{id} /$ minute.

\subsection{Assay of NADPH Oxidase Activity}

NOX activity was measured according to the method established by Reusch and Burger [19]. Briefly, a cocktail was prepared with $200 \mu \mathrm{L}$ of phosphate buffer, $200 \mu \mathrm{L}$ of nano-pure water and $50 \mu \mathrm{L}$ of EDTA. Then $25 \mu \mathrm{L}$ of serum and $25 \mu \mathrm{L}$ of NADPH were added. Immediately, the absorbance was taken at $340 \mathrm{~nm}$ and recorded for 5 minutes. One unit of NOX is defined as the amount of enzyme required to oxidize $1.0 \mu$ mole of NADPH per minute and expressed as U/L.

\subsection{Determination of Nitric Oxide}

Endothelium-derived NO level was determined using the Griess Reagent System, as described previously [20].

\subsection{Assay of HDL Cholesterol}

The serum HDL-C was assayed by using the reagent Kits from Randox Laboratories Ltd., UK, and the recommended protocol was followed for the determination. 


\subsection{Assay of Ceruloplasmin Activity}

The enzymatic activity of serum ceruloplasmin was measured using O-dianisidine dihydrochloride as a substrate and was expressed as U/L [21].

\subsection{Assay of Myeloperoxidase Activity}

The plasma MPO activity was measured by a colorimetric assay using O-dianisidine as a substrate, according to Bradley et al. [22], and detailed previously [23]. The MPO activity of the samples was expressed in Units/mg of protein.

\subsection{Assay of Glutathione Reductase Activity}

GR activity can be determined by using NADPH, which is oxidized to $\mathrm{NADP}^{+}$ by the catalytic activity of glutathione reductase. One unit of GR activity is defined as a change in optical density of 0.001 per $\mathrm{mL}$ per minute at $340 \mathrm{~nm}$ [24].

\subsection{Statistical Analysis of the Data}

GraphPad Prism (version 7.0 for Windows, GraphPad software, USA) was used for carrying out independent samples t-test for comparison of the two groups and graphical presentation of the analyzed data, chi-square $\left(\chi^{2}\right)$ test was used for comparison of categorical variables. The Spearman correlation analysis was done using the Statistical Package for Social Sciences (version 20.0 for Windows, SPSS Inc., USA). The mean \pm SD values were calculated for each parameter. The results were considered significant when $\mathrm{p}$ was $<0.05$.

\section{Results}

\subsection{Baseline Characteristics of the Study Subjects}

Among the enrolled 60 patients, 45 (75\%) had STEMI, 12 (20\%) had NSTEMI and $3(5 \%)$ had unstable angina (UA). The general health information of the study subjects were recorded on preformed questionnaire forms (Appendix). These include the body weight, height, systolic blood pressure (SBP), diastolic blood pressure (DBP), age, smoking status, previous history of hypertension (HTN), family history of cardiovascular diseases (CVD), breathlessness, and history of myocardial infarction. The troponin I values of the patients, which were measured at the hospital upon diagnosis, were also recorded. A comparison of the baseline characteristics of the study participants is shown in Table 1. It was found that the SBP, DBP, BMI (body mass index, $\mathrm{kg} / \mathrm{m}^{2}$ ), and family history of CVD were not significantly different between the ACS patients and controls while smoking and previously diagnosed HTN emerged as significant risk factors for the development of ACS. It was found that the mean age of the patients, $51.0 \pm 10.5$ years (ranging from 26 to 70 years), was significantly higher than the controls.

\subsection{Serum Xanthine Oxidase Activity}

In the control group, the mean serum XO activity was $48.51 \pm 13.41 \mathrm{mU} / \mathrm{mL}$ 
Table 1. Baseline characteristics of the control subjects and ACS patients.

\begin{tabular}{cccc}
\hline Variables & $\begin{array}{c}\text { Control Subjects } \\
(\mathrm{N}=60)\end{array}$ & $\begin{array}{c}\text { ACS Patients } \\
(\mathrm{N}=60)\end{array}$ & Statistics \\
\hline BMI $\left(\mathrm{kg} / \mathrm{m}^{2}\right)$ & $\begin{array}{c}\text { General information }(\text { Mean } \pm \text { SD }) \\
\text { SBP }(\mathrm{mmHg})\end{array}$ & $26.2 \pm 1.5$ & $\mathrm{NS}$ \\
DBP $(\mathrm{mmHg})$ & $122.4 \pm 9.9$ & $129.5 \pm 31.1$ & $\mathrm{NS}$ \\
Age (years) & $81.2 \pm 7.0$ & $83.9 \pm 18.7$ & $\mathrm{NS}$ \\
Troponin I (ng/mL) & $41.5 \pm 12.3$ & $51.0 \pm 10.5$ & $\mathrm{p}<0.001$ \\
& $\mathrm{ND}$ & $14.3 \pm 25.6$ & $\mathrm{NA}$ \\
Non-smokers & 55.00 & & \\
Ex-smokers & 8.33 & 25.00 & $\mathrm{p}<0.0001$, \\
Current smokers & 36.67 & 23.33 & $\chi^{2}=21.09$ \\
& 10.00 & 51.67 & \\
Previously diagnosed HTN & 15.00 & 50.00 & $\mathrm{p}<0.0001$ \\
Family history of CVD & 11.67 & 28.33 & $\mathrm{NS}$ \\
Breathlessness & 0 & 23.33 & $\mathrm{NS}$ \\
Previous history of MI & Cardiology information $(\%)$ & 18.33 & $\mathrm{NA}$ \\
\hline
\end{tabular}

NS: not significant; ND: not done; NA: not applicable; HTN: hypertension; MI: myocardial infarction.

whereas the value was $158.03 \pm 43.30 \mathrm{mU} / \mathrm{mL}$ in the ACS patients, which was significantly higher (Figure 1(a)).

\subsection{RBC Lysate Xanthine Oxidase Activity}

The mean RBC lysate XO activity was $184.10 \pm 70.14 \mathrm{mU} / \mathrm{mL}$ in the controls and the value was $309.07 \pm 75.73 \mathrm{mU} / \mathrm{mL}$ in the ACS patients, which was significantly higher (Figure $1(\mathrm{~b})$ ).

\subsection{Serum NADPH Oxidase Activity}

The mean serum NOX activity in the ACS patients was $14.13 \pm 3.38 \mathrm{U} / \mathrm{L}$ which was significantly higher than $6.90 \pm 1.94 \mathrm{U} / \mathrm{L}$ found in the controls (Figure 2).

\subsection{Levels of Nitric Oxide}

The mean nitric oxide level in ACS patients was $5.62 \pm 2.72 \mu \mathrm{M}$ and that in the control subjects was $10.24 \pm 5.94 \mu \mathrm{M}$, implying that the patients had significantly lower value $(\mathrm{p}<0.0001)$.

\subsection{Evaluation of HDL-Cholesterol}

The mean serum HDL-C level in the ACS patients was $21.67 \pm 6.88 \mathrm{mg} / \mathrm{dL}$ and the corresponding value in the control subjects was $29.81 \pm 4.43 \mathrm{mg} / \mathrm{dL}$. Statistical analysis of the data showed HDL-C level was significantly lower in ACS patients (Figure 3). 


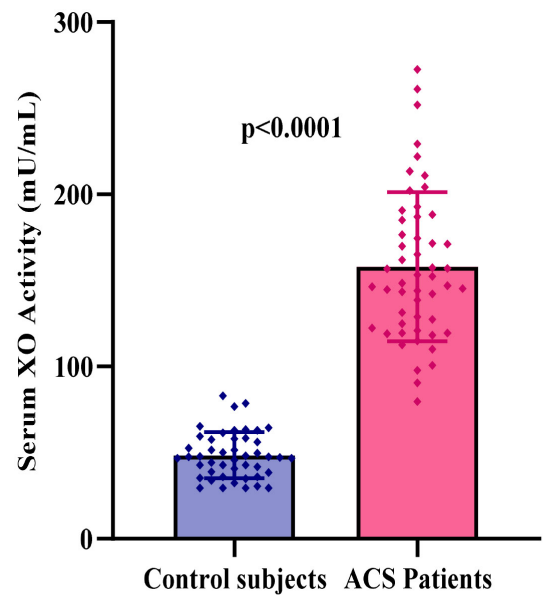

(a)

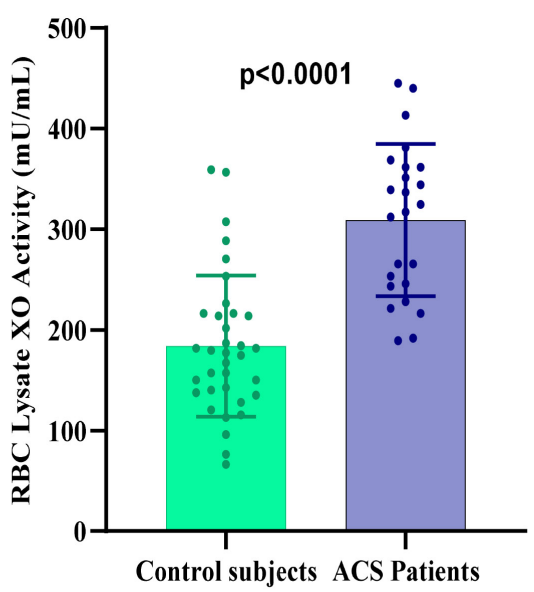

(b)

Figure 1. Comparison of xanthine oxidase (XO) activities in (a) serum and (b) RBC lysates of the ACS patients and control subjects.

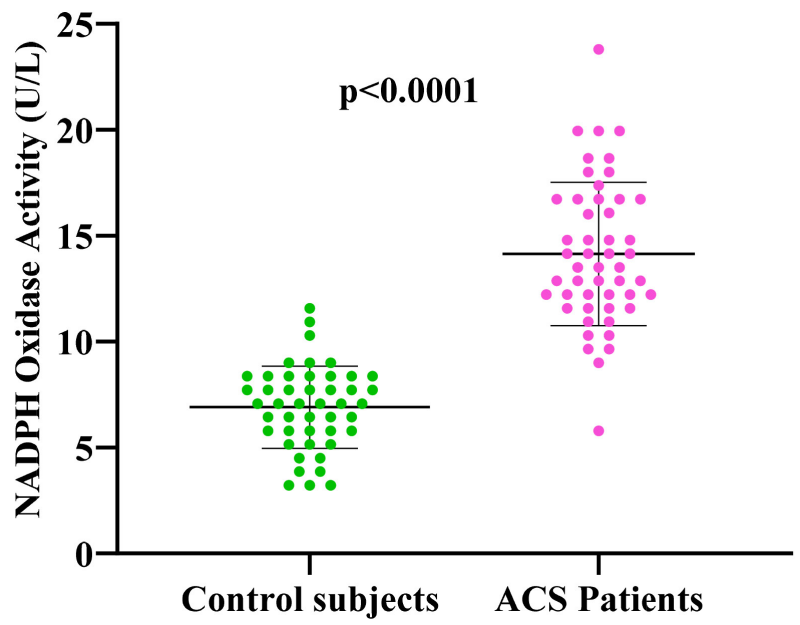

Figure 2. NADPH oxidase (NOX) activity in serum of the control subjects and ACS patients.

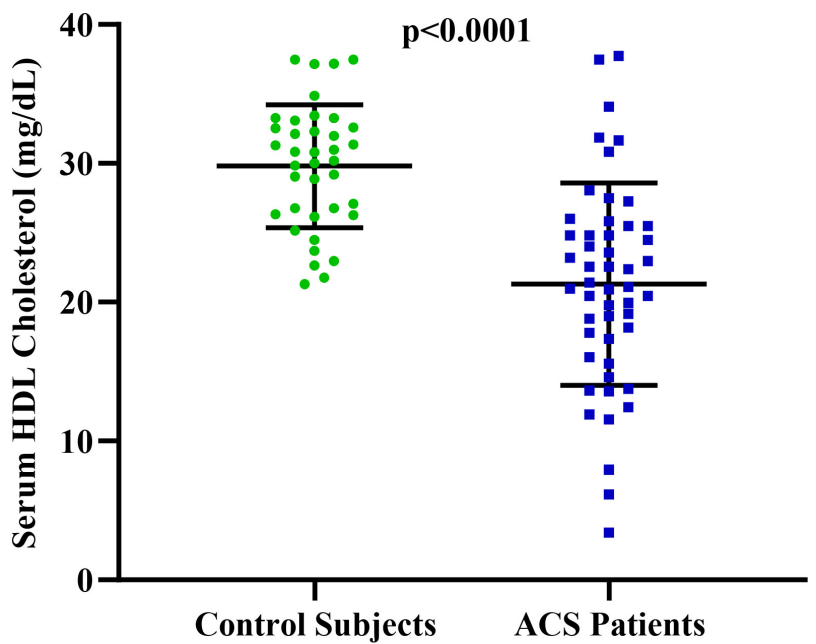

Figure 3. HDL cholesterol levels in the study groups showing significantly lower value ( $\mathrm{p}$ $<0.0001)$ in ACS patients than the control subjects. 


\subsection{Ceruloplasmin Activity}

The mean ceruloplasmin activity of the controls was $70.0 \pm 18.9 \mathrm{U} / \mathrm{L}$ and that of the patients was $83.8 \pm 26.2 \mathrm{U} / \mathrm{L}$, which was significantly higher $(\mathrm{p}<0.05)$.

\subsection{Myeloperoxidase Activity}

The mean MPO activity of the controls was $5.9 \pm 1.5 \mathrm{U} / \mathrm{mg}$ while the corresponding value of the patients was $10.9 \pm 3.3 \mathrm{U} / \mathrm{mg}$, which was significantly higher $(\mathrm{p}<0.001)$.

\subsection{Glutathione Reductase Activity}

The mean GR activity of the controls was $85.2 \pm 49.5 \mathrm{U} / \mathrm{mL} / \mathrm{min}$ and that in the patients was $60.7 \pm 47.8 \mathrm{U} / \mathrm{mL} / \mathrm{min}$, which was significantly lower $(\mathrm{p}<0.05)$.

\subsection{Correlation of Oxidase Enzymes and Antioxidative Stress Biomarkers}

A significant negative correlation was found between circulatory XO and GR activities in ACS patients, with a Spearman correlation coefficient rho of -0.371 (Figure 4). There were significant positive correlations between serum $\mathrm{XO}$ and NOX, and RBC lysate XO with NO in ACS patients but significant negative correlations were found between NOX and GR, and NO with HDL-C in ACS patients (Table 2). A weak positive correlation (rho $=0.054$ ) was shown by $\mathrm{RBC}$ lysate XO with plasma MPO activity in ACS patients.

In the control subjects, serum $\mathrm{Cp}$ and $\mathrm{RBC}$ lysate $\mathrm{XO}$ activities showed a significant negative correlation but the $\mathrm{Cp}$ showed a significant positive correlation with plasma GR activity (Table 2). Further, a significant positive correlation was found between RBC lysate XO and plasma MPO activities in control subjects (Figure 5). In contrast to the ACS patients, there was a significant positive correlation between HDL-C and nitric oxide in the controls (Table 2).

Table 2. Correlation of oxidase enzymes and antioxidative stress biomarkers.

\begin{tabular}{ccccc}
\hline \multirow{2}{*}{$\begin{array}{c}\text { Spearman } \\
\text { rho correlation }\end{array}$} & $\begin{array}{c}\text { Serum XO } \\
(\mathrm{mU} / \mathrm{mL})\end{array}$ & $\begin{array}{c}\text { RBC lysate XO } \\
(\mathrm{mU} / \mathrm{mL})\end{array}$ & $\begin{array}{c}\text { Plasma GR } \\
(\mathrm{U} / \mathrm{mL} / \mathrm{min})\end{array}$ & $\begin{array}{c}\text { Nitric Oxide } \\
(\text { micro } \mathrm{M})\end{array}$ \\
\cline { 2 - 5 } & & ACS patients: & \\
NOX $(\mathrm{U} / \mathrm{L})$ & $0.461(\mathrm{p}<0.01)$ & $-0.340(\mathrm{p}=0.122)$ & $-0.315(\mathrm{p}<0.05)$ & \\
GR $(\mathrm{U} / \mathrm{mL} / \mathrm{min})$ & $-0.371(\mathrm{p}<0.01)$ & $0.227(\mathrm{p}=0.309)$ & & $-0.317(\mathrm{p}<0.05)$ \\
RBC_XO $(\mathrm{mU} / \mathrm{mL})$ & & & $0.227(\mathrm{p}=0.309)$ & $0.550(\mathrm{p}<0.01)$ \\
HDL-C $(\mathrm{mg} / \mathrm{dL})$ & $0.153(\mathrm{p}=0.289)$ & $-0.287(\mathrm{p}=0.195)$ & $0.143(\mathrm{p}=0.333)$ & $-0.302(\mathrm{p}<0.05)$ \\
& & Control subjects: & & $0.119(\mathrm{p}=0.436)$ \\
Ceruloplasmin $(\mathrm{U} / \mathrm{L})$ & & $-0.344(\mathrm{p}<0.05)$ & $0.388(\mathrm{p}<0.05)$ & $0.252(\mathrm{p}=0.095)$ \\
MPO $(\mathrm{U} / \mathrm{mg})$ & & $0.337(\mathrm{p}<0.05)$ & & $0.376(\mathrm{p}<0.05)$ \\
HDL-C $(\mathrm{mg} / \mathrm{dL})$ & $-0.069(\mathrm{p}=0.68)$ & & & \\
NOX $(\mathrm{U} / \mathrm{L})$ & $0.242(\mathrm{p}=0.105)$ & $0.186(\mathrm{p}=0.284)$ & & \\
\hline
\end{tabular}




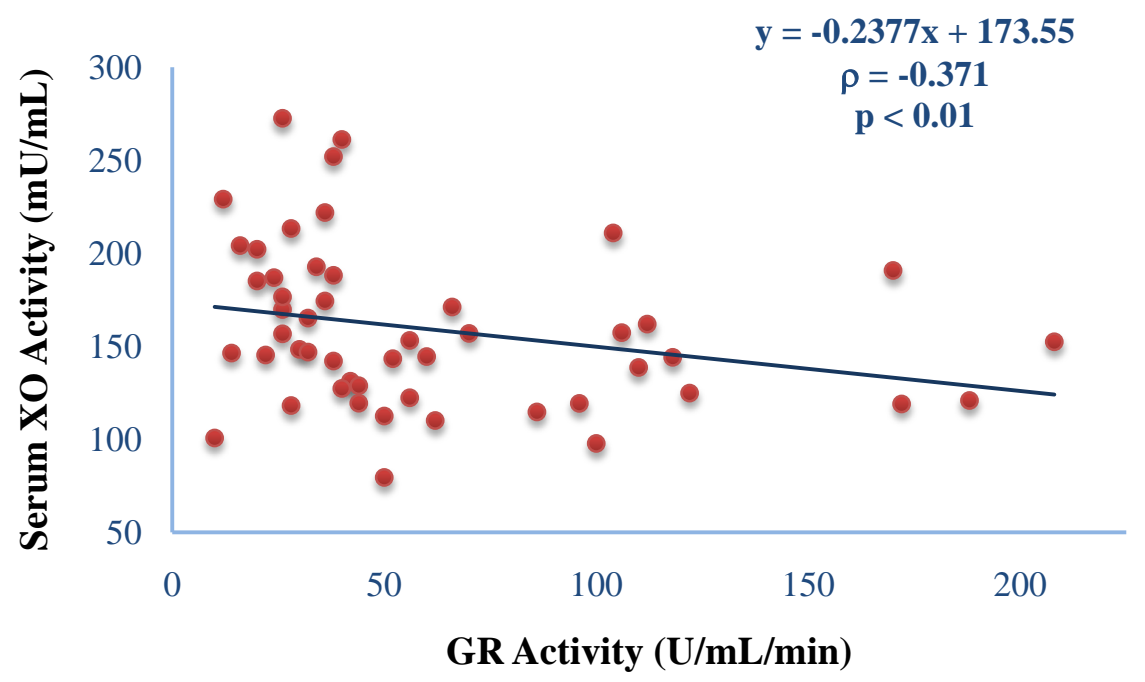

Figure 4. A significant negative correlation of xanthine oxidase with glutathione reductase (GR) activities in ACS patients $(\rho=-0.371, \mathrm{p}<0.01)$.

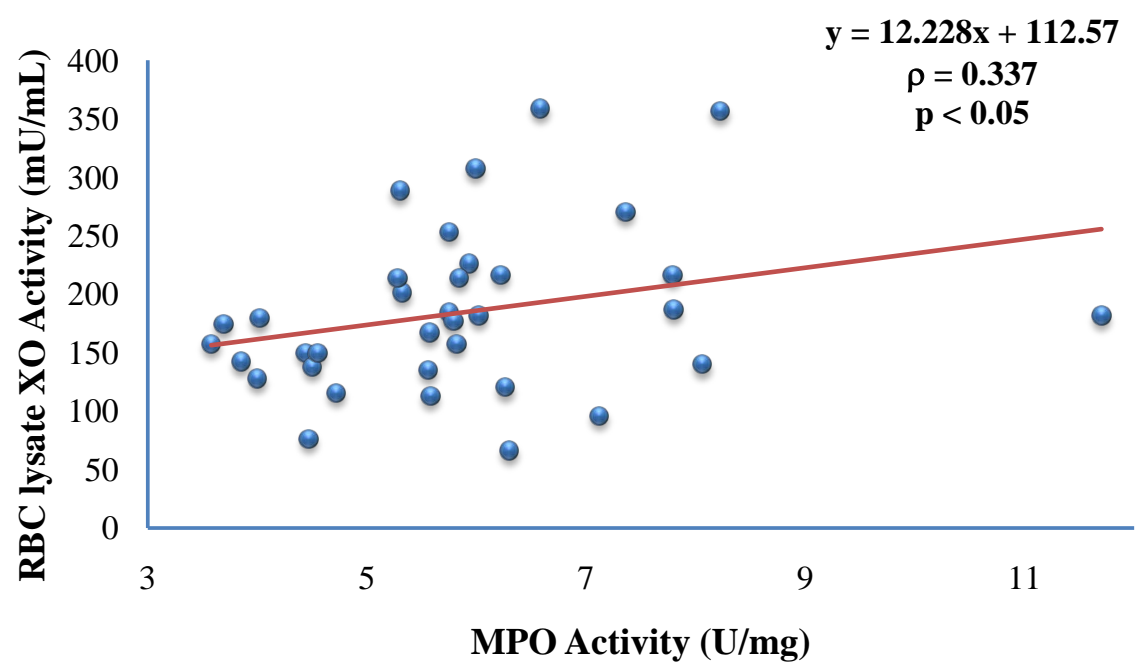

Figure 5. A significant positive correlation of RBC lysate XO with MPO activities in control subjects $(\rho=0.337, \mathrm{p}<0.05)$.

\section{Discussion}

This study investigated the activities of different oxidase enzymes, inflammatory biomarker ceruloplasmin $(\mathrm{Cp})$ and their correlation with other antioxidative stress biomarkers in patients with acute coronary syndrome (ACS). The mean age of the patient group was 51.0 years, which was significantly higher than the controls. It may be mentioned that due to stringent inclusion criteria, it was difficult to obtain samples from age-matched control subjects. Further, smoking and previously diagnosed hypertension appeared to be significant risk factors for the development of ACS, as reported earlier [20] [25].

Previous investigators observed that the vascular NADPH oxidase (NOX) was linked to the pathological states associated with hypertension and endothelial 
dysfunction of atherosclerosis [5] [26]. The results of the present study revealed that patients with ACS exhibited significantly higher NOX activity compared to the controls. It had been reported that heart failure led to an increase in NOX activity releasing excessive ROS in the circulation [27]. Therefore, increased activity of NOX was clearly associated with the underlying pathogenesis of ACS in patients.

In this study $\mathrm{XO}$ activity was found to be significantly higher in both serum and erythrocyte of ACS patients compared to controls. Although one study investigated XO activity in healthy volunteers [28], no study was made in the CVD patients. Therefore, the XO activity reported in this study could not be compared with other researches. However, there was an evidence of increased XO activity in diabetic rats [29], a lot of research had been going on to reduce CVD complications by inhibiting XO activity [30].

A reduced nitric oxide $(\mathrm{NO})$ bioavailability, either due to a decrease in $\mathrm{NO}$ synthesis or an increase in NO utilization owing to locally enhanced production of ROS, is a pronounced hallmark of endothelial dysfunction [31]. It has been found that NO prevents atherosclerosis by inhibiting platelet aggregation and adhesion, inhibiting leukocyte adhesion and migration, and reducing vascular smooth muscle proliferation [32]. All major risk factors for atherosclerosis such as hyperlipidemia, diabetes, hypertension, and smoking have been found associated with reduced NO bioavailability [33]. In the current study, the nitric oxide level was significantly lower in the ACS patients, which was consistent with previous findings [20] [34].

Lipid abnormalities or dyslipidemia, including low levels of HDL-C, are associated with an increased risk of ACS. In the current study, the ACS patients had significantly lower serum HDL-C levels compared to controls. Previous investigators reported a decreased serum HDL-C level to be an independent predictor of endothelial dysfunction in atherosclerosis [35]. Since HDL-C is thought to exert atheroprotective effects via its action on the endothelium [36], HDL-C raising interventions should, therefore, be evaluated as a novel therapeutic strategy in patients with CAD.

One of the critical findings of this study was a significantly higher Cp levels in ACS patients. This observation is consistent with the findings of another study in similar patients [15]. An early study by Fox et al. [13] has investigated the role of human $\mathrm{Cp}$ in oxidative processes because of its function as the principal copper-containing protein in serum. Their study has shown that $\mathrm{Cp}$ is a potent catalyst of LDL oxidation in vitro.

It has been found that the main sources of CVD-ROS are NOX and XO [37]. In oxidative stress, they are the ones producing excessive superoxide in ACS patients. Accordingly, the present study found a significant positive correlation between serum XO and NOX activities in ACS patients. This observation suggested that both XO and NOX activities increased in patients synergistically for the establishment of oxidative stress, as reported earlier [37]. A similar conclu- 
sion can be drawn from the positive correlations between MPO and RBC lysate $\mathrm{XO}$ in both ACS patients and control subjects, since MPO is also an enzyme responsible for catalyzing the formation of ROS.

A recent study found that a lower antioxidant response was associated with atherosclerosis and CAD [38]. Glutathione reductase (GR) is responsible for the regeneration of potent antioxidant, glutathione. Therefore, it might be possible that GR activity would be lower in ACS patients having impaired antioxidant capacity. This study found a significantly decreased activity of GR in the patient group which also showed significant negative correlations with both $\mathrm{XO}$ and NOX, the two main sources of ROS. These observations indicate that lower GR activity together with higher oxidase activities simultaneously hinder the balance between ROS and antioxidants.

In this study, a significant positive correlation was found between HDL-C and nitric oxide in the controls, suggesting that normal HDL-C from healthy subjects activates the production of the anti-atherosclerotic and anti-thrombotic signaling molecule nitric oxide. Interestingly, a significant negative correlation was found between HDL-C and nitric oxide in ACS patients, supporting a previous finding that HDL-C from patients with atherosclerotic diseases caused no increase or an actual decrease in endothelial nitric oxide [36]. These authors suggested that HDL-C of CAD patients activated endothelial lectin-like oxidized LDL receptor 1, which in turn inhibited endothelial nitric oxide synthase-dependent NO production.

In this study, $\mathrm{Cp}$ showed a significant negative correlation with RBC lysate $\mathrm{XO}$ activity in the control subjects. This observation is in agreement with a study by Samokyszyn et al. [39] which suggested that Cp can inhibit XO. According to Kennedy et al. [40], Cp can show both pro-oxidant and antioxidant capacity and there might be a homeostatic balance between the two states that prevails under different conditions. As a pro-oxidant, NO oxidase function of $\mathrm{Cp}$ may predominate which promotes nitrative stress and disease progression, while as an antioxidant, $\mathrm{Cp}$ can remove free ferrous iron and therefore can reduce a major producer of superoxide and hydroxyl radicals. This might also explain another observation of this study which revealed a significant positive correlation between Cp and GR in control subjects.

\section{Summary and Conclusion}

The present study highlighted the extent of oxidative stress due to excessive production of ROS by the oxidase enzymes, XO, NOX and MPO. Endothelial dysfunction was evident from the decreased NO levels in the ACS patients who had low HDL-C. The present study attempted to explain the role of inflammation in ACS patients by the elevated levels of ceruloplasmin. Finally, the correlations strongly supported the theory of the imbalance created between oxidants and antioxidants in favor of oxidants leading to increased oxidative stress in patients with ACS. 


\section{Limitations}

One of the limitations of the present study was the small sample size. Due to the need to perform the tests on fresh samples, it was not possible to collect and store a larger number of samples. Secondly, the mean age of the ACS patients was significantly higher than the control subjects.

\section{Acknowledgements}

This study was supported by a research grant allocated by the University Grants Commission of Bangladesh. NF, MEKA and NNB are recipients of National Science \& Technology Fellowships.

\section{Conflicts of Interest}

The authors declare no conflicts of interest regarding the publication of this paper.

\section{References}

[1] Reddy, K.S. (2002) Cardiovascular Diseases in the Developing Countries: Dimensions, Determinants, Dynamics and Directions for Public Health Action. Public Health Nutrition, 5, 231-237. https://doi.org/10.1079/PHN2001298

[2] Khanam, F., Hossain, M., Mistry, S., Afsana, K. and Rahman, M. (2019) Prevalence and Risk Factors of Cardiovascular Diseases among Bangladeshi Adults: Findings from a Cross-Sectional Study. Journal of Epidemiology and Global Health, 9, 176-184. https://doi.org/10.2991/jegh.k.190531.001

[3] Vassalle, C., Pratali, L., Boni, C., Mercuri, A. and Ndreu, R. (2008) An Oxidative Stress Score as a Combined Measure of the Pro-Oxidant and Anti-Oxidant Counterparts in Patients with Coronary Artery Disease. Clinical Biochemistry, 41, 1162-1167. https://doi.org/10.1016/j.clinbiochem.2008.07.005

[4] González-Montero, J., Brito, R., Gajardo, A. and Rodrigo, R. (2018) Myocardial Reperfusion Injury and Oxidative Stress: Therapeutic Opportunities. World Journal of Cardiology, 10, 74-86. https://doi.org/10.4330/wjc.v10.i9.74

[5] Griendling, K., Sorescu, D. and Ushio-Fukai, M. (2000) NAD(P)H Oxidase. Circulation Research, 86, 494-501. https://doi.org/10.1161/01.RES.86.5.494

[6] McCord, J. and Fridovich, I. (1988) Superoxide Dismutase: The First Twenty Years (1968-1988). Free Radical Biology and Medicine, 5, 363-369. https://doi.org/10.1161/01.RES.86.5.494

[7] Loria, V., Dato, I., Graziani, F. and Biasucci, L. (2008) Myeloperoxidase: A New Biomarker of Inflammation in Ischemic Heart Disease and Acute Coronary Syndromes. Mediators of Inflammation, 2008, Article ID: 135625. https://doi.org/10.1155/2008/135625

[8] Teng, N., Maghzal, G., Talib, J., Rashid, I., Lau, A. and Stocker, R. (2016) The Roles of Myeloperoxidase in Coronary Artery Disease and Its Potential Implication in Plaque Rupture. Redox Report, 22, 51-73. https://doi.org/10.1080/13510002.2016.1256119

[9] Meister, A. and Anderson, M. (1983) Glutathione. Annual Review of Biochemistry, 52, 711-760. https://doi.org/10.1146/annurev.bi.52.070183.003431

[10] Zuzak, E., Horecka, A., Kiełczykowska, M., Dudek, A., Musik, I., Kurzepa, J. and 
Kurzepa, J. (2017) Glutathione Level and Glutathione Reductase Activity in Serum of Coronary Heart Disease Patients. Journal of Pre-Clinical and Clinical Research, 11, 103-105. https://doi.org/10.26444/jpccr/81277

[11] Peluffo, G. and Radi, R. (2007) Biochemistry of Protein Tyrosine Nitration in Cardiovascular Pathology. Cardiovascular Research, 75, 291-302.

https://doi.org/10.1016/j.cardiores.2007.04.024

[12] Gandotra, P. and Miller, M. (2008) The Role of Triglycerides in Cardiovascular Risk. Current Cardiology Reports, 10, 505-511. https://doi.org/10.1007/s11886-008-0079-0

[13] Fox, P., Mazumder, B., Ehrenwald, E. and Mukhopadhyay, C. (2000) Ceruloplasmin and Cardiovascular Disease. Free Radical Biology and Medicine, 28, 1735-1744. https://doi.org/10.1016/S0891-5849(00)00231-8

[14] Xu, Y., Lin, H., Zhou, Y., Cheng, G. and Xu, G. (2013) Ceruloplasmin and the Extent of Heart Failure in Ischemic and Nonischemic Cardiomyopathy Patients. $\mathrm{Me}$ diators of Inflammation, 2013, Article ID: 348145. https://doi.org/10.1155/2013/348145

[15] Sirajwala, H.B., Dabhi, A.S., Malukar, N.R., Bhalgami, R.B. and Pandya, T.P. (2007) Serum Ceruloplasmin Level as an Extracellular Antioxidant in Acute Myocardial Infarction. Journal of Indian Academy of Clinical Medicine, 8, 135-138.

[16] Bustamante, J.B., Martín, M.M. and de Quirós Fernández, J.B. (1975) Copper, Cerulopasmin and Zinc in Relation to the Metabolism of Lipids in Arteriosclerotic Patients. Revista Clinica Espanola, 139, 243-246.

[17] Reunanen, A., Knekt, P. and Aaran, R.K. (1992) Serum Ceruloplasmin Level and the Risk of Myocardial Infarction and Stroke. American Journal of Epidemiology, 136, 1082-1090. https://doi.org/10.1093/oxfordjournals.aje.a116573

[18] Bergmeyer, H.U., Gawehn, K. and Grassl, M. (1974) 3-Hydroxyacyl-CoA Dehydrogenase. Methods of Enzymatic Analysis, 1, 474.

[19] Reusch, V.M. and Burger, M.M. (1974) Distribution of Marker Enzymes between Mesosomal and Protoplast Membranes. Journal of Biological Chemistry, 249, 5337-5345.

[20] Kamruzzaman, M., Choudhury, T.Z., Rahman, T. and Islam, L.N. (2019) A Cross-Sectional Study on Assessment of Oxidative Stress in Coronary Heart Disease Patients in Bangladesh. World Journal of Cardiovascular Diseases, 9, 331-342. https://doi.org/10.4236/wjcd.2019.95029

[21] Schosinsky, K., Lehmann, H. and Beeler, M. (1974) Measurement of Ceruloplasmin from Its Oxidase Activity in Serum by Use of o-Dianisidine Dihydrochloride. Clinical Chemistry, 20, 1556-1563. https://doi.org/10.1093/clinchem/20.12.1556

[22] Bradley, P., Priebat, D., Christensen, R. and Rothstein, G. (1982) Measurement of Cutaneous Inflammation: Estimation of Neutrophil Content with an Enzyme Marker. Journal of Investigative Dermatology, 78, 206-209. https://doi.org/10.1111/1523-1747.ep12506462

[23] Choudhury, T.Z, Kamruzzaman, M. and Islam, L.N. (2018) Investigation of the Cellular and Soluble Markers of Inflammation for the Assessment of Cardiovascular Risk in Patients with Acute Coronary Syndrome in Bangladesh. International Journal of Immunological Studies, 2, 1. https://doi.org/10.1504/IJIS.2018.10016181

[24] Manso, C. and Wróblewski, F. (1958) Glutathione Reductase Activity in Blood and Body Fluids. Journal of Clinical Investigation, 37, 214-218.

https://doi.org/10.1172/JCI103600 
[25] Fatema, K., Zwar, N.A., Milton, A.H., Ali, L. and Rahman, B. (2016) Prevalence of Risk Factors for Cardiovascular Diseases in Bangladesh: A Systematic Review and Meta-Analysis. PLoS ONE, 11, e0160180. https://doi.org/10.1371/journal.pone.0160180

[26] Sahoo, S., Meijles, D. and Pagano, P. (2016) NADPH Oxidases: Key Modulators in Aging and Age-Related Cardiovascular Diseases? Clinical Science, 130, 317-335. https://doi.org/10.1042/CS20150087

[27] Borchi, E., Bargelli, V., Stillitano, F., Giordano, C., Sebastiani, M., Nassi, P., d'Amati, G., Cerbai, E. and Nediani, C. (2010) Enhanced ROS Production by NADPH Oxidase Is Correlated to Changes in Antioxidant Enzyme Activity in $\mathrm{Hu}-$ man Heart Failure. Biochim Biophysica Acta (BBA) Molecular Basis of Disease, 1802, 331-338. https://doi.org/10.1016/j.bbadis.2009.10.014

[28] Cecerska-Heryć, E., Jesionowska, A., Klaudyna, S., Katarzyna, S., Dominika, M.P., Marta, U. and Dołęgowska, B. (2015) Xanthine Oxidoreductase Reference Values in Platelet-Poor Plasma and Platelets in Healthy Volunteers. Oxidative Medicine and Cellular Longevity, 2015, Article ID: 341926. https://doi.org/10.1155/2015/341926

[29] Aliciguzel, Y., Ozen, I., Aslan, M. and Karayalcin, U. (2003) Activities of Xanthine Oxidoreductase and Antioxidant Enzymes in Different Tissues of Diabetic Rats. Journal of Laboratory and Clinical Medicine, 142, 172-177. https://doi.org/10.1016/S0022-2143(03)00110-0

[30] Schuchardt, M., Herrmann, J., Tolle, M. and der Giet, M. (2017) Xanthine Oxidase and Its Role as Target in Cardiovascular Disease: Cardiovascular Protection by Enzyme Inhibition? Current Pharmaceutical Design, 23, 3391-3404. https://doi.org/10.2174/1381612823666170417130115

[31] Davignon, J. and Ganz, P. (2004) Role of Endothelial Dysfunction in Atherosclerosis. Circulation, 109, 27-32. https://doi.org/10.1161/01.CIR.0000131515.03336.f8

[32] Toda, N., Tanabe, S. and Nakanishi, S. (2011) Nitric Oxide-Mediated Coronary Flow Regulation in Patients with Coronary Artery Disease: Recent Advances. The International Journal of Angiology, 20, 121-134. https://doi.org/10.1055/s-0031-1283220

[33] Kawashima, S. and Yokoyama, M. (2004) Dysfunction of Endothelial Nitric Oxide Synthase and Atherosclerosis. Arteriosclerosis, Thrombosis, and Vascular Biology, 24, 998-1005. https://doi.org/10.1161/01.ATV.0000125114.88079.96

[34] Akarasereenont, P., Nuamchit, T., Thaworn, A., Leowattana, W., Chotewuttakorn, S. and Khunawat, P. (2002) Serum Nitric Oxide Levels in Patients with Coronary Artery Disease. Journal of the Medical Association of Thailand, 84, S730-S739.

[35] Eren, E., Yılmaz, N., Aydin, O. and Ellidağ, H.Y. (2014) Anticipatory Role of High Density Lipoprotein and Endothelial Dysfunction: An Overview. The Open Biochemistry Journal, 8, 100-106. https://doi.org/10.2174/1874091X01408010100

[36] Besler, C., Heinrich, K., Rohrer, L., Doerries, C., Riwanto, M., Shih, D.M., Chroni, A., Yonekawa, K., Stein, S., Schaefer, N., et al. (2011) Mechanisms Underlying Adverse Effects of HDL on eNOS-Activating Pathways in Patients with Coronary Artery Disease. Journal of Clinical Investigation, 121, 2693-2708. https://doi.org/10.1172/JCI42946

[37] Cervantes Gracia, K., Llanas-Cornejo, D. and Husi, H. (2017). CVD and Oxidative Stress. Journal of Clinical Medicine, 6, pii: E22. https://doi.org/10.3390/jcm6020022

[38] Pellegrino, D. (2016) Antioxidants and Cardiovascular Risk Factors. Diseases, 4, 11. https://doi.org/10.3390/diseases4010011 
[39] Samokyszyn, V.M., Miller, D.M., Reif, D.W. and Aust, S.D. (1989) Inhibition of Superoxide and Ferritin-Dependent Lipid Peroxidation by Ceruloplasmin. Journal of Biological Chemistry, 264, 21-26.

[40] Kennedy, D.J., Fan, Y., Wu, Y., Pepoy, M., Hazen, S.L. and Tang, W.W. (2014) Plasma Ceruloplasmin, a Regulator of Nitric Oxide Activity, and Incident Cardiovascular Risk in Patients with CKD. Clinical Journal of the American Society of Nephrology, 9, 462-467. https://doi.org/10.2215/CJN.07720713

\section{Appendix}

\section{Questionnaire Form for Blood Sample Collection}
Entry No.:
Patient ID:
Date of Admission:

A. General Information:

\begin{tabular}{|l|l|}
\hline Name: & Sex: Male/ Female \\
\hline Address: & Height $(\mathrm{cm}):$ \\
\hline Contact No.: & Weight $(\mathrm{kg}):$ \\
\hline Age (years): & Profession: \\
\hline
\end{tabular}

B. Information about Risk Factors:

\begin{tabular}{|c|c|c|c|c|c|}
\hline 1. & Smoking Status: & Current & & Ex-smoker & Never \\
\hline 2. & Smokeless Tobacco: & Current & & Ex-smoker & Never \\
\hline 3. & Hypertension: & Yes & No & \multicolumn{2}{|c|}{ If yes, how long: } \\
\hline 4. & Breathlessness: & Yes & No & & \\
\hline 5. & Alcohol consumption: & Yes & No & \multicolumn{2}{|c|}{ If yes, how long: } \\
\hline 6. & Family History of CVD: & Yes & No & \multicolumn{2}{|c|}{ Father/Mother/Brother/Sister } \\
\hline 7. & Dietary Intake (days/week): & Red me & Cken & $\mathrm{sh} / \mathrm{Egg} / \mathrm{Veget}$ & s/Fruits/Pulse \\
\hline
\end{tabular}

C. Clinical Information (on admission):

\begin{tabular}{|l|ll|}
\hline 1. & Duration of Chest Pain: & Pulse Rate: \\
\hline 2. & Blood Pressure (mm Hg): & \multicolumn{1}{c|}{ Blood Glucose/FBS } \\
\hline 3. & Myocardial Infarction (MI) Type: & STEMI/ NSTEMI/ UA \\
\hline 4. & Previous History of MI: & Yes / No \\
\hline 5. & Previous History of Angina: & Yes / No \\
\hline 6. & Cardiac Troponin I Level $(\mathrm{ng} / \mathrm{mL}):$ & \\
\hline
\end{tabular}

